\title{
ISOLATION AND IDENTIFICATION OF A CITRATO-COMPLEX OF NICKEL FROM NICKEL-ACCUMULATING PLANTS
}

\author{
Julian LeE*, Roger D. REeves*, Robert R. Brooks* and TANGUY JAFFrÉ $\dagger$ \\ *Department of Chemistry, Biochemistry and Biophysics, Massey University, Palmerston North, New Zealand; \\ †Centre O.R.S.T.O.M., Nouméa, New Caledonia
}

(Received 3 March 1977)

Key Word Index-Sebertia acuminata; Sapotaceae; Homalium species; Flacourtiaceae; nickel-accumulating plants; citrato-nickelate complex.

\begin{abstract}
An organometallic complex of nickel has been isolated from nickel-accumulating plants of New Caledonia and has been identified by a combination of infrared spectroscopy, high-voltage paper electrophoresis, gas-liquid chromatography and mass spectrometry. Most of the nickel in Sebertia acuminata, Homalium francii, Homalium guillainii, Homalium kanaliense, Hybanthus austrocaledonicus and Hybanthus caledonicus is found as a negativelycharged citratonickelate (II) complex with $\mathrm{Ni}\left(\mathrm{H}_{2} \mathrm{O}\right)_{6}^{2+}$ as the major cationic constituent.
\end{abstract}

\section{INTRODUCTION}

The uptake and translocation of elements such as nickel by plants is of considerable interest, and the need for efforts to identify carriers of this and other elements in xylem fluids has been noted [1]. Certain plant species can accumulate remarkably high concentrations of one or more of these elements, up to $10-25 \%$ (dry-weight basis) in the extreme case of the nickel content of the New Caledonian species Sebertia acuminata Pierre ex Baill. The presence of such high concentrations raises interesting questions in plant chemistry and is a major factor stimulating research into the chemical form of transition elements in plants. Much of the existing information has come from electrophoretic experiments using radioactive tracers because of the generally low physiological levels of these elements. Unidentified anionic complexes of nickel and copper occur in xylem exudates of plants such as tomato, cucumber and peanut [2]. Anionic forms of copper and zinc have been found in ryegrass extracts [3] and much of the zinc in extracts of Ricinus communis is bound to anionic organic complexes, possibly containing phosphorus $[4]$. Tiffin $[1,5]$ found that iron (III) in several plant exudates showed the same electrophoretic behaviour as anionic iron (III)-citrate complexes, but suggested $[1,6]$ that amino acids act as carriers for copper and nickel, as these elements show a particular affinity for nitrogen-containing ligands. Lyon et al. [7] identified three anionic complexes of chromium in Leptospermum scoparium of which the major one was trioxalatochromium (III). Farago et al. [8], using paper chromatography with ammonium oxalate extracts of Hybanthus floribundus, showed the presence of a nickel compound with $R_{f}$ similar to that of nickel pectinate but also noted the possibility that nickel was associated with amino acids. However no association between nickel and amino acids was found by Kelly et al. [9] in their study of Hybanthus species from New Caledonia. Severne [10] studied the composition of nickel complexes in $H$. floribundus and although he was not able to isolate a pure complex, he deduced that nickel was in the form of a complex of low molecular weight. Perhaps the most significant advances to date in the elucidation of the structure of nickel complexes in accumulator plants are to be found in the work of Pelosi et al. [11,12] who studied extracts of Alyssum bertolonii Desv. and deduced that nickel was complexed with organic acids such as malic and malonic acids.

In the present work, we report the results of studies carried out on the nature of nickel complexes extracted from six species of accumulator plants from New Caledonia, all of which normally contain nickel concentrations in their leaves and latex, well in excess of $1000 \mu \mathrm{g} / \mathrm{g}$ $(0.1 \%)$ expressed on a dry-weight basis. The following were studied: Sebertia acuminata - [13], Hybanthus austrocaledonicus Schinz et Guillaumin, Hybanthus caledonicus (Turcz.) Cretz., Homalium francii Guillaumin, Homalium guillainii Briq., and Homalium kanaliense Briq. Hyperaccumulation of nickel by most of these species has been reported by Brooks et al. [14]. In each case the complexes were purified by chromatography on Sephadex G-10 or G-25.$$
\text { .6 }
$$

\section{IDENTIFICATION OF NICKEL COMPLEXES}

The IR spectra of a solution of the nickel complex showed in every case, carboxylate stretching frequencies at $1590 \mathrm{~cm}^{-1}$ and $1430 \mathrm{~cm}^{-1}$ as well as frequencies characteristic of $\mathrm{H}_{2} \mathrm{O}$ bending and $\mathrm{OH}$ stretching vibrations. The MS of the effluent from the gas chromatograph of the TMS derivatives of the complex showed the presence of a single peak with only traces of impurities. The spectrum showed a peak of highest mass at $m / e=$ 465 , derived from a molecular ion of mass 480 (the molecular ion peak is often entirely absent from spectra of hydroxyacid TMS derivatives [15] from which the largest detectable fragment is that formed by loss of -Me). Accurate measurement of the masses of several fragments led to a mass of 480.185 and molecular formula

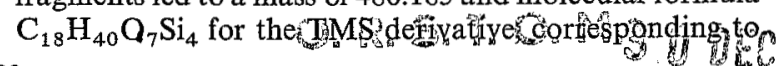




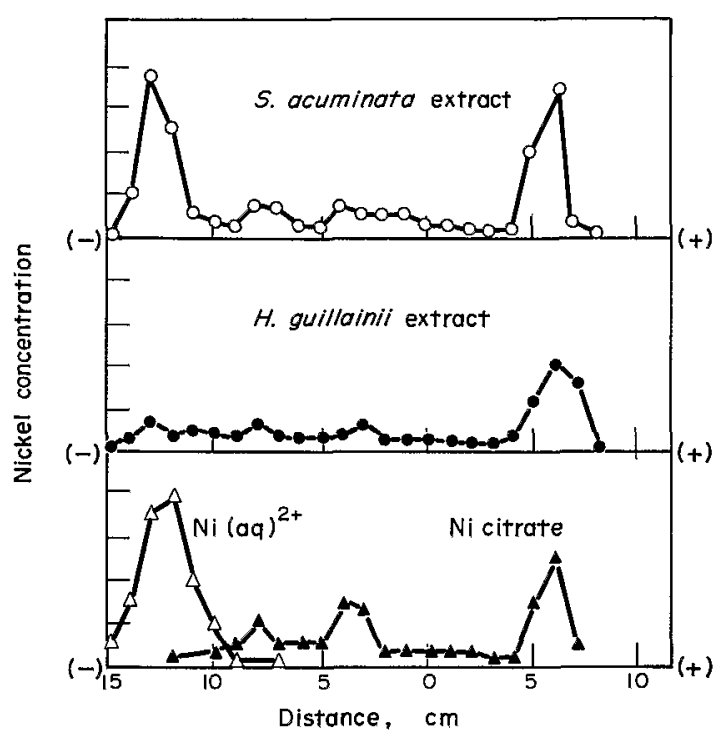

Fig. 1. Electrophoretic distribution of nickel in extracts of $S$. acuminata $(\mathrm{O})$ and $\mathrm{H}$. guillainii $(\bullet)$, compared with $\mathrm{Ni}\left(\mathrm{H}_{2} \mathrm{O}\right)_{6}^{2+}$ $(\triangle)$ and a $2: 1$ citrate:nickel solution (A). Pyridine/acetic acid/water at $\mathrm{pH} 6.5,3 \mathrm{kV}, 40 \mathrm{~min}$, Whatman No. 1 paper.

a parent compound $\mathrm{C}_{6} \mathrm{H}_{8} \mathrm{O}_{7}$. Known compounds of this formula include the saccharic acid monolactones, citric acid and isocitric acid. GLC of TMS derivatives of monolactones of galactaric acid and glucaric acid, using OV-101, gave retention times approximately twice those of the unknown TMS derivative, which was inseparable from derivatives of citric and isocitric acids on both OV-101 and OV-17. However, the MS clearly showed the presence of citrate in the nickel-containing plant extracts. The major peaks in the spectrum of silylated citric acid correspond to those reported previously [16].

Experiments with high-voltage paper electrophoresis (Fig. 1) show the behaviour of the nickel at $\mathrm{pH} 6.5$ in two of the plant extracts, compared with $\mathrm{Ni}\left(\mathrm{H}_{2} \mathrm{O}\right)_{6}^{2+}$ and with nickel in a $2: 1$ citrate/nickel solution. The combined evidence of GLC and electrophoresis showed the presence of an anionic citrato-complex of nickel in the purified extracts of all the nickel-containing plants noted above. Varying amounts of $\mathrm{Ni}\left(\mathrm{H}_{2} \mathrm{O}\right)_{6}^{2+-}$ were also present. Mass spectrometric confirmation of the identity of the citrate was carried out for the extracts from $S$. acuminata and $H$. austrocaledonicus.

The electrophoretic behaviour and the elemental analysis of the plant extracts are consistent with the presence of citratonickelate(II), the counter-cations being a mixture of $\mathrm{Ni}\left(\mathrm{H}_{2} \mathrm{O}\right)_{6}^{2+}$ and hydrated $\mathrm{Mg}^{2+}$ and $\mathrm{Ca}^{2+}$. Where the extracts contain only low concentrations of magnesium and calcium ( $<1 \%$ of the solid), as in the case of the latex of $S$. acuminata, the nickel analysis and electrophoresis indicate that $\mathrm{Ni}\left(\mathrm{H}_{2} \mathrm{O}\right)_{6}^{2+}$ is the major cationic constituent.

The $\mathrm{Ni}\left(\mathrm{H}_{2} \mathrm{O}\right)_{6}^{2+}$ can be removed by passing the extracts through a weak cation exchange gel (Sephadex CM-25). The absorption spectra $(340-740 \mathrm{~nm})$ of the resulting solutions correspond to those of a $2: 1$ citrate/ nickel solution and differ from those of $\mathrm{Ni}\left(\mathrm{H}_{2} \mathrm{O}\right)_{6}^{2+}$ and $1: 1$ citrate/nickel solutions.

We have observed that the nickel electrophoretograms of Tiffin [2] closely resemble those of plant extracts shown in Fig. 1. It appears probable that the nickel carrier in the plants studied by Tiffin is also a citratocomplex, and that translocation of nickel by citrate is not confined to those plants which accumulate high concentrations, but is a more universal occurrence.

In attempting to elucidate the structure of a metalorganic complex in plant material the question always arises as to whether the complex was formed metabolically or whether it is an artefact of the extraction process. One way to approach this problem is to examine the spatial distribution of metal concentrations and then check to see whether the organic ligand has the same distribution. Electron-probe measurements on leaves of several of the New Caledonian accumulator species showed that nickel was always distributed in a uniform manner without concentration at specific sites and the above method of approach was clearly inoperable. However, since the nickel-citrate complex was clearly evident in the latex of $S$. acuminata which was used directly without use of extraction procedures, there is no reason to suppose that presence of the same complex in the leaves of this and other species is the result of non-metabolic formation.

If, as has been suggested, translocation of nickel by citrate is a universal characteristic of most plant species, this finding should have significance in fields other than plant chemistry or plant physiology. Considerable research is now under way throughout the world on the problem of extracting nickel from ores by low-energy processes, and it may be possible that complexing of this metal as citrate is a mechanism which should be explored for such a purpose.

\section{EXPERIMENTAL}

Extraction of complexes. To prevent Ni complexes appearing as an artefact in the separation process extraction of macerated fresh or freeze-dried leaf material was carried out with $\mathrm{H}_{2} \mathrm{O}$ at room temp. $50-70 \%$ of the total Ni could readily be extracted under these conditions. The extracts were shaken with $\mathrm{CHCl}_{3}$ $n$-BuOH (10:1) to remove high molecular weight compounds of low polarity. Negligible amounts of Ni were lost in this process.

Chromatography. The aq. soln was reduced in vol. and passed through a Sephadex G-10 or G-25 column. The latex from $S$. acuminata was passed through a filter paper directly on to a Sephadex G-50 column. $\mathrm{H}_{2} \mathrm{O}$ was used to elute the columns, again to reduce the possibility of complex formation between the extracted $\mathrm{Ni}$ and any added reagents. The green Ni-containing fraction was recycled through the column several times before being taken to dryness at room temp.

IR spectra. Because microanalysis of the solids showed the $\mathrm{N}$ content to be immeasurably small, the possibility of amino acids being involved was eliminated and IR spectra were recorded to identify frequency characteristics of specific groupings.

GLC-MS. In the presence of trifluoroacetic acid, $10-30 \mathrm{mg}$ of the Ni complex was reacted with $N$-(trimethylsilyl)imidazole in dimethyl sulphoxide as solvent, giving a trimethylsilyl (TMS) derivative of the organic ligand in the upper clear layer of the reaction mixture. GLC $\left(170^{\circ}\right.$, glass column with $1.5 \%$ OV-101 on Chromosorb W, AW-DMCS, 100-120 mesh) using a $1 \mu \mathrm{l}$ aliquot of the upper layer, was used to check the TMS derivatives. The gas chromatograph was connected to a MS which was run at $20 \mathrm{eV}$, separator temp. $160^{\circ}$.

High-voltage electrophoresis. High voltage paper electrophoresis was carried out on the extracted $\mathrm{Ni}$ complexes, and on $\mathrm{Ni}$ chloride and $\mathrm{Ni}$ citrate solutions, using a Savant-type apparatus. Experimental conditions are given in the caption to Fig. 1. 
Acknowledgements--The authors are indebted to Drs. L. Nixon, I. G. Andrew, R. T. Gallagher, and Professor R. Hodges for advice and assistance.

\section{REFERENCES}

1. Tiffin, L. O. (1972) in Micronutrients in Agriculture (Mortyedt, J. J., Giordano, P. M. and Lindsay, W. L. eds.), p. 199. Soil Sci. Soc. Amer., Madison, Wis.

2. Tiffin, L. O. (1971) Plant Physiol. 48, 273.

3. Bremner, I. and Knight, A. H. (1970) Brit. J. Nutr. 24, 279.

4. Van Goor, B. J. and Wiersma, D. (1976) Physiol. Plantarum 36, 213.

5. Tiffin, L. O. (1970) Plant Physiol. 45, 280.

6. Thompson, J. F. and Tiffin, L. O. (1974) Plant Physiol. Suppl. 23.

7. Lyon, G. L., Brooks, R. R. and Peterson, P. J. (1969) Planta 88, 282.
8. Farago, M. E., Clark, A. J. and Pitt, M. J. (1975) Co-ord. Chem. Rev. 16, 1.

9. Kelly, P. C., Brooks, R. R., Dilli, S. and Jaffré, T. (1975) Proc. Roy. Soc. Lond. B189, 69.

10. Severne, B. C. (1972) PhD Thesis, Massey University, Palmerston North, New Zealand.

11. Pelosi, P., Galoppini, C. and Vergnano Gambi, O. (1974) L'Agricoltura Italiana 29, 1.

12. Pelosi, P., Fiorentini, R. and Galoppini, C. (1976) Agric. Biol. Chem. 40, 1641.

13. Jaffré T., Brooks, R. R., Lee, J. and Reeves, R. D. (1976) Science 193, 579.

14. Brooks, R. R., Lee, J., Reeves, R. D. and Jaffré, T. (1977) J. Geochem. Explor. 7, 49.

15. Petersson, G. (1970) Tetrahedron 26, 3413.

16. Mamer, O. A., Crawhall, J. C. and SanTjoa, S. (1971) Clin. Chim. Acta 32, 171 